\title{
PENTINGNYA VARIASI TATA LETAK DAN GARNISH PADA HIDANGAN TERHADAP TINGKAT KEPUASAN TAMU DI HOTEL HORISON ULTIMA MALANG
}

\author{
Antonius Bayu Kartiko1) \\ Estikowati $\left.{ }^{2}\right)$ \\ Program Diploma Kepariwisataan Universitas Merdeka Malang1 \\ Jl. Bandung No. 1 Malang
}

Korespodensi dengan Penulis:

Antonius Bayu Kartiko: Telp: 089679003119

E-mail: bayukartiko94@gmail.com

\begin{abstract}
In food presentation, especialy in a restaurant and a hotel, required human resource who have artistic's soul, creativity, and high profesionalism. Thus food layout and garnish' variation can increase guest's satisfaction. But now food layout and garnish are often forgotten. The writter want to know the importance of food layout and garnish for guest satisfaction and guest's response to food that are served. The Writter used primary and secondary data collection's method and then analyzed using descriptivequalitative method. The lack of human resources who understand the art of food production, limit variety of food layout and garnish. And then increase guest's surfeit who have become rugular guest. For the guests food layout and garnish are important think and proportional against guest's satisfaction.

Keywords : Variety, Layout, Garnish, Food, Guest Satisfy.
\end{abstract}

Hidangan adalah sebuah kebutuhan pokok yang dibutuhkan oleh manusia, baik untuk kebutuhan jiwa dan kebutuhan raga. Seluruh kebutuhan tenaga dan perasaan dapat didapat dari hidangan. Oleh karena itu hidangan menjadi bagian penting dalam proses metabolisme tubuh dan perasaan manusia dalam mendukung seluruh kegiatan manusia yang sangat membutuhkan banyak tenaga disertai dukungan perasaan.

Salah satu alat penunjang dalam sebuah hidangan adalah tata letak dan garnish hidangan diatas piring saji. Sebagai dekorasi dalam sebuah hidangan di atas piring saji, tata letak dan garnish berfungsi sebagai faktor 
pendukung dalam sebuah sajian hidangan selain rasa, yang berguna mempercantik hidangan demi pendukung perasaan konsumen saat menyantap hidangan tersebut. Berdasarkan fungsi tata letak dan garnish, yang sangat penting dalam sebuah sajian hidangan maka harus ada pengelolaan dan pengembangan yang baik dari segi pemilihan bahan, macam bentuknya, dan fungsinya selain sebagai dekorasi hidangan.

Pengelolaan serta pengembangan tata letak dan garnish yang baik dapat menunjang peningkatan nilai seni dalam sebuah olahan hidangan yang seringkali diabaikan dengan berbagai macam alasan. Berbagai kendala seperti kurangnya sumber daya manusia yang memiliki rasa seni, terbatasnya bahan kreasi akibat biaya produksi, alat-alat yang kurang menunjang, menjadi alasan buruknya pengelolaan tata letak dan garnish di sebagian restoran yang berdiri sendiri maupun restoran yang berada di dalam hotel. Kondisi ini semakin parah dengan adanya pemikiran "yang palig penting dari sebuah hidangan adalah rasa". Rasa memang adalah bagian penting dari sebuah hidangan namun seni penyajian juga adalah hal yang penting untuk menciptakan keidahan dan nafsu makan yang lebih.

Problema-problema tersebut tentu sangat meperihatinkan, karena berimbas pada citra yang tidak baik di bidang bisnis boga. Padahal bidang inilah salah satu penyumbang devisa pada industri pariwisata. Kepuasan pelanggan hanya akan menjadi anganangan apabila tidak dilakukan perbaikan maupun pengembangan dalam pengelolaan tata letak dan garnish hidangan.

\section{METODE}

Dari judul dan perumusan masalah sudah tergambar pada penelitian ini penulis menggunakan dua variabel yaitu pentingnya variasi tata letak dan garnish pada hidangan dan kepuasan pelaggan. Sedangkan indikator dalam penelitian ini adalah:

1) Adapun indikator pentingnya variasi tata letak dan garnish pada hidangan variabel adalah bebas:
a) Keindahan
b) Detail
c) Pilihan Bahan Baru 
2) Sedangkan indikator kepuasan pelanggan variabel terikat adalah:

a) Reaksi Pelanggan

b) Emosi Pelanggan

c) Presepsi Pelanggan

Hotel Horison Ultima Malang yang terletak di Jalan Green Boulevard No. 02 Kota Araya, Malang, Jawa Timur, Telephone : +62 341417272 Faximile : +62 341 480339. Sebelah utara berhadapan dengan Rumah Sakit Persada, sebelah selatan dan timur berdeketan dengan perumahan mewah warga, dan sebelah barat berdekatan dengan Plaza Araya. Penulis menjadi karyawan trainee di Main Kitchen Section dari Food and Beverage Product Department. Metode pengumpulan data yang akan dilakukan meliputi:

1. Observasi Partisipasi: Adalah metode pengumpulan data dengan cara terjun langsung dan merasakan menjadi anggota kelompok yang diteliti. Penulis langsung terjun sebagai karyawan magang. Penulis melakukan penelitian dari 10 November 201410 Januari 2015.

2. Teknik Wawancara: Pengumpulan data yang dilakukan dengan tanya jawab langsung kepada pihak karyawan.

3. Angket: Cara pengumpulan data dengan memberikan beberapa daftar pertanyaan yang bersangkutan dengan penelitian kepada responden yaitu tamu yang menginap dua hari atau lebih di Hotel Horison Ultima Malang untuk di isi. Dengan tujuan frekuensi memesan makanan di Hotel Horison Ultima Malang lebih banyak.

4. Dokumentasi: Metode pengumpulan data dengan mengambil bukti foto yang digunakan sebagai alat pendukung penelitian.

Setelah data dari lapangan terkumpul dengan menggunakan metode pengumpulan data yang digunakan, maka peneliti mengolah dan menganalisis data tersebut dengan menggunakan analisis secara deskriptifkualitatif, tanpa menggunakan teknik kuantitatif.

\section{HASIL}

Hotel Horison ultima adalah hotel yang berdiri dibawah Metropolitan Golden Management 
dan berdiri pada tanggal 22 Mei 2003. Hotel Horison Ultima Malang sendiri berdiri pada tanggal 18 Februari yang terletak di Jalan Green Boulevard No. 2 Araya, Malang.

\section{Tata Letak dan Garnish Hidangan} di Hotel Horison Ultima Malang

Pada Hotel Horison Ultima Malang menyediakan berbagai macam menu. Terdiri atas hidangan pembuka, sup, hidangan utama, hidangan penutup, serta menyediakan makanan ringan. Garnish yang biasa digunakan pada berbgai hidangan adalah bunga mawar dari kulit tomat, selada keriting yang disusun, crouton, arranged halfcut tomato and cucumber, parsley, seledri, daun pisang, dan bawang goreng. Sedangkan plating atau tata letak yang sering digunakan adalah piring saji menggunakan circle, square, oval plate; makanan disusun memenuhi setiap ruang piring saji dan saus di letakkan pada cangkir aladin. Biasanya tata letak dan garnish tersebut digunakan di menu ala carte dan buffet.

\section{Perolehan Data}

Data yang diperoleh dengan menyebar angket kepada responden yaitu dari para tamu yang menginap dua hari atau lebih di Hotel Horison Ultima Malang yang ditunjukkan sebagai berikut :

Tabel 1: Pernyataan Status Tamu

\begin{tabular}{|c|c|c|c|c|c|}
\hline \multirow{3}{*}{ No } & \multirow{3}{*}{ Pernyataan } & \multicolumn{4}{|c|}{ Penilaian } \\
\hline & & \multicolumn{2}{|c|}{$\mathrm{Ya}$} & \multicolumn{2}{|c|}{ Tidak } \\
\hline & & $\mathrm{F}$ & $\%$ & $\mathrm{~F}$ & $\%$ \\
\hline 1. & $\begin{array}{l}\text { Tamu adalah seseorang yang } \\
\text { bergerak di bidang tata boga }\end{array}$ & 0 & $0 \%$ & 10 & $100 \%$ \\
\hline
\end{tabular}

Sumber: Tamu Hotel Horison Ultima Malang yang menginap lebih dari dua hari Jumlah yang diteliti : : 10 Orang (N)

Rumus $\quad: \mathrm{F} \div \mathrm{N} \times 100 \%$

Keterangan : F adalah jumlah frekuensi yang menyetakan "Ya" atau "Tidak"

$\mathrm{N}$ adalah total responden

Keterangan Jawaban: Jawaban "Ya" adalah negatif dan jawaban "Tidak" adalah positif. 


\section{Keterangan Tabel 1 :}

Responden adalah seseorang yang tidak bergerak di bidang tata boga. $0=0 \%$ responden menyatakan "Ya" dan 10=100\% responden menyatakan "Tidak".

Dari data yang didapat, rata-rata jawaban adalah "Tidak" berjumlah 10 orang, maka dapat disimpulkan responden adalah subjek penelitian netral.

Tabel 2: Pernyataan Pandangan Umum Pentingnya Variasi Tata Letak dan Garnish pada Hidangan Terhadap Kepuasan Tamu

\begin{tabular}{|l|l|l|l|l|l|}
\hline \multirow{2}{*}{ No } & \multicolumn{1}{|c|}{ Pernyataan } & \multicolumn{4}{c|}{ Penilaian } \\
\cline { 3 - 6 } & \multicolumn{1}{|c|}{ Ya } & \multicolumn{2}{|c|}{ Tidak } \\
\cline { 3 - 6 } & $\begin{array}{l}\text { Makanan yang memiliki keindahan, detail, } \\
\text { dan pilihan bahan baru pada tata letak dan } \\
\text { garnishnya membuat tamu puas. }\end{array}$ & & $80 \%$ & 2 & $20 \%$ \\
\hline 2 & $\begin{array}{l}\text { Keindahan, detail, dan pilihan bahan baru } \\
\text { pada tata letak dan garnish adalah hal yang } \\
\text { bisa menunjang nafsu makan tamu. }\end{array}$ & 10 & $100 \%$ & 0 & $0 \%$ \\
\hline 3 & $\begin{array}{l}\text { Akan muncul presepsi positif dari tamu jika } \\
\text { makanan memiliki keindahan, detail dan } \\
\text { pilihan bahan baru pada tata letak dan } \\
\text { hiasannya }\end{array}$ & 7 & $70 \%$ & 3 & $30 \%$ \\
\hline
\end{tabular}

Sumber : 10 Tamu Hotel Horison Ultima Malang yang menginap lebih dari dua hari

Jumlah yang diteliti $\quad$ :10 Orang $(\mathrm{N})$

Rumus $: \mathrm{F} \div \mathrm{N} \times 100 \%$

Keterangan : F adalah jumlah frekuensi yang menyetakan "Ya" atau "Tidak" $\mathrm{N}$ adalah total responden

Keterangan Jawaban: Jawaban "Ya" adalah positif dan jawaban "Tidak" adalah negatif.

Keterangan Tabel 2 :

1. Makanan yang tidak memiliki keindahan, Detail, dan pilihan bahan baru pada tata letak dan garnishnya membuat responden kurang puas. $8=80 \%$ responden menyatakan "Ya" dan 2=20\% responden menyatakan "Tidak". Dapat disimpulkan bahwa keindahan, Detail, dan pilihan bahan baru pada tata letak dan garnish berpengaruh pada emosi 
pelanggan terutama pada emosi atau perasaan puas.

2. Keindahan, Detail, dan pilihan bahan baru pada tata letak dan garnish adalah hal yang bisa menunjang nafsu makan responden. 10 $=100 \%$ responden menyatakan "Ya" dan $0=0 \%$ menyatakan "Tidak". Dapat disimpulkan bahwa keindahan, Detail dan pilihan bahan baru pada tata letak dan garnish bisa menunjang nafsu makan.

3. Kemunculan presepsi positif dari tamu jika makanan memiliki keindahan, Detail, dan pilihan bahan baru pada tata letak dan hisanya. $\quad 7=70 \% \quad$ responden menyatakan "Ya" dan 3=30\% menyatakan "Tidak". Dapat dismpulkan bahwa hidangan yang baik dan lengkap serta memiliki nilai seni dapat menimbulkan presepsi positif.

Dari 3 jenis pertanyaan dan 10 orang responden, sehingga ada 30 pertanyaan. Ada 25 jawaban "Ya" dan 5 jawaban "Tidak". Maka rata-rata jawaban "Ya" dengan persentase 83,3\% dan "Tidak" dengan persentase 26,7\%. Dapat diartikan bahwa tata letak dan garnish adalah hal yang penting dalam suatu hidangan.

Tabel 3: Pernyataan Pandangan Khusus Tamu Terhadap Variasi Tata Letak dan Garnish pada Hidangan di Hotel Horison Ultima Malang

\begin{tabular}{|c|c|c|c|c|c|}
\hline \multirow{3}{*}{ No } & \multirow{3}{*}{ Pernyataan } & \multicolumn{4}{|c|}{ Penilaian } \\
\hline & & \multicolumn{2}{|c|}{ Ya } & \multicolumn{2}{|c|}{ Tidak } \\
\hline & & $\mathrm{F}$ & $\%$ & $\mathrm{~F}$ & $\%$ \\
\hline 1 & $\begin{array}{l}\text { Hidangan yang dipesan tamu memiliki tata } \\
\text { letak dan garnish yang memiliki keindahan, } \\
\text { detail, dan pilihan bahan baru. }\end{array}$ & 2 & $20 \%$ & 8 & $80 \%$ \\
\hline 2 & $\begin{array}{l}\text { Dari makanan yang tamu pesan, tamu akan } \\
\text { menuntaskan menyantap makanan } \\
\text { meskipun makanan yang disajikan tidak } \\
\text { memiliki detail, keindahan, dan pilihan } \\
\text { bahan baru pada tata letak dan garnishya }\end{array}$ & 4 & $40 \%$ & 6 & $60 \%$ \\
\hline 3 & $\begin{array}{l}\text { Keindahan, detail dan pilihan bahan baru } \\
\text { dari makanan yang tamu pesan, membuat } \\
\text { tamu berpresepsi bahwa hotel sudah } \\
\text { memberikan makanan yang bernilai tinggi } \\
\text { sesuai dengan standart hotel bintang } 4\end{array}$ & 3 & $30 \%$ & 7 & $70 \%$ \\
\hline
\end{tabular}

Sumber : Tamu Hotel Horison Ultima Malang yang menginap lebih dari dua hari

Jumlah yang diteliti $\quad$ :10 Orang $(\mathrm{N})$ 
Rumus

Keterangan
$: \mathrm{F} \div \mathrm{N} \times 100 \%$

: F adalah jumlah frekuensi yang menyetakan "Ya" atau "Tidak"

$\mathrm{N}$ adalah total responden

Keterangan Jawaban: Jawaban "Ya" adalah positif dan jawaban "Tidak" adalah negatif.

Keterangan Tabel 3 :

1. Hidangan yang responden pesan memiliki tata letak dan garnish yang memiliki keindahan, Detail, dan pilihan bahan baru. 2=20\% responden menyatakan "Ya" dan $8=80 \%$ responden menyatakan “Tidak". Dapat disimpulakan responden merasa kurang puas dengan hidangan yang mereka pesan.

2. Dari makanan yang responden pesan, apakah responden akan menuntaskan menyantap makanan meskipun makanan yang disajikan memiliki Detail, keindahan, dan pilihan bahan baru pada tata letak dan garnishya. 4=40\% menyatakan "Ya" dan 6=60\% menyatakan “Tidak". Dapat disimpulkan bahwa Detail, keindahan, dan pilihan bahan baru pada tata letak dan garnish dapat menciptakan reaksi negatif karena berkurangnya nafsu makan responden.

3. Keindahan, Detail dan pilihan bahan baru pada tata letak dan garnish dari makanan yang responden pesan membuat responden berpresepsi bahwa hotel memberikan makanan yang bernilai tinggi sesuai dengan standart hotel bintang 4 . 3=30\% responden menyatakan "Ya" dan 7=70\% menyatakan "Tidak". Dapat dismpulkan bahwa sebagaian besar responden berpresepsi negatif pada hidangan yang disediakan.

Dari 3 jenis pertanyaan dan 10 orang responden, sehingga ada 30 pertanyaan. Ada 9 jawaban "Ya" dan 21 jawaban "Tidak". Maka rata-rata jawaban "Ya" dengan persentase 70\% dan "Tidak" dengan persentase 30\%. Dapat diartikan bahwa makanan yang disajikan oleh hotel belum memenuhi keinginginan tamu dari segi tata letak dan garnish.

\section{PEMBAHASAN}

Variasi tata letak dan garnish yang ada juga merupakan salah satu unsur untuk memenuhi selera dan tingkat kepuasan tamu akan seni 
dalam suatu hidangan. Kurangnya sumber daya manusia yang mengerti seni hidangan serta kurangnya dukungan dari Supervisor/ Chef de Partie dan Executve Chef terhadap staff Main Kitchen dan Pastry and Bakery Section sehingga kurang memiliki motivasi untuk berkreasi dan berinovasi terhadap variasi tata letak dan garnish, baik kreasi dan inovasi dalam teknik pengolahan, pemilihan bahan, kesesuaian dengan hidangan dan kesesuaian terhadap biaya.

\section{Bukti Masalah}

Dari data yang didapat dari tabel 1, subjek penelitian adalah netral. Subjek penelitian yang netral menjawab sesuai dengan apa yang benar-benar dirasakan dan dilihat. Maka dari itu peneliti bisa mendapatkan hasil yang akurat.

Dari pernyataan umum yang diberikan oleh responden, 83,3\% menyatakan bahwa tata letak dan garnish adalah hal yang dapat menunjang kualitas dari suatu makanan. Tata letak dan garnish menjadi penting dalam meningkatkan kepuasan tamu. Sedangkan 26,7\% menganggap tata letak dan garnish bukanlah hal yang terlalu penting dalam penyajian hidangan.

Pernyataan khusus yang diutarakan oleh responden, sebgaian besar menanggapi negatif dengan hidangan yang sudah disajikan oleh Hotel Horison Ultima Malang. $\quad 70 \% \quad$ responden menyatakan bahwa makanan yang disajikan oleh hotel masih belum memenuhi standart nilai seni makanan bintang empat. Serta $30 \%$ responden sudah menyatakan puas dengan hidangan yang di sajikan.

Dapat di tarik kesimpulan bahwa dari 10 orang responden yang tidak bergerak dibidang tata boga, menganggap variasi tata letak dan garnish adalah hal yang penting. Namun yang didapatkan responden, masih jauh dari keinginan responden.

\section{Akibat Masalah}

Adapun akibat yang muncul dari kurang bervariasinya tata letak dan garnish pada hidangan di Hotel Horison Ultima Malang yaitu kurang puasnya sebagian tamu. Hal ini besar andil karena 
kurangnya sumber daya manusia yang mengerti tentang seni boga dan dukungan dari Supervisor/Chef de Partie dan Executive Chef untuk mendorong karyawannya menciptakan kreasi dan inovasi pada tata letak dan garnish makanan.

\section{Langkah Pemecahan Masalah}

Berdasar dari sebab dan akibat masalah yang ada penulis menentukan solusi yaitu meningkatkan kualitas sumber daya manusianya. Dengan cara pihak personalia meningkatkan kualitas syarat penerimaan pegawai Food and Beverage Product Department dengan memilih calon karyawan yang bukan hanya mengerti teknik tata boga namun juga mengerti seni dari tata boga, serta diharapkan Chef de Partie dan Executif Chef mau belajar dan membimbing sumber daya yang sudah ada supaya karyawan tersebut memiliki semangat dan motivasi lebih untuk berkreasi dan berinovasi pada tata letak dan garnish sebagai seni boga dan alat penunjang kepuasan pelanggan.

\section{Hasil yang Diharapkan}

Sesuai dengan langkah pemecahan masalah yang diberikan penulis berharap agar Hotel Horison mendapat sumber daya baru yang lebih mengertai Detail dari tata boga dan supaya Chef de Partie dan Executive Chef dari Horison Ultima membimbing karyawannya agar bisa menciptakan karya baru pada kreasi tata letak dan garnish hidangan. Serta pada akhirnya berharap supaya meningkatnya tingkat kepuasan pelanggan di Hotel Horison Malang.

\section{KESIMPULAN DAN SARAN}

\section{Kesimpulan}

a. Tingkat kepuasan pelanggan di Hotel Horison Ultima Malang masih belum mendapat tanggapan baik, karena tata letak dan garnish pada hidangan kurang memenuhi keinginan tamu. Sebagian besar responden memberi komentar negatif pada makanan yang sudah dipesan.

b. Bervariasinya tata letak dan garnish berbanding lurus terhadap tingkat kepuasan pelanggan 
dengan sampel yang menginap lebih dari dua hari. Semakin banyak variasi tata letak dan garnish pada hidangan semakin membuat keinginan pelanggan untuk terus mengkonsumsi makanan dari Hotel Horison Ultima Malang sehingga pendapatan semakin tinggi dari sektor selain penjualan kamar.

\section{Saran}

Adapun saran yang dapat diberikan penulis melalui penelitian yang sudah dilakukan adalah:

a. Bagi Hotel

1. Pihak personalia

mau meningkatkan kualifikasi penerimaan karyawan, supaya hasil produk Food and Beverage Product Department yang dihasilkan hotel lebih memiliki kualitas tinggi dari seni dan teknik pengolahan.

2. Chef de Partie dan Executive Chef disarakan untuk mau membimbing karyawan yang sudah ada dengan baik, supaya lebih mengerti tentang seni tata boga.
3. Pengawasan yang harus dilakukan terus menerus dan dengan baik agar, proses peningkatan kepuasan pelanggan mencapai target maksimal

b. Bagi Lembaga

Lembaga DIII/DIV Kepariwisataan diharapkan mengajarkan tata letak dan garnish yang lebih bervariasi supaya di industri, mahasiswa lebih siap menjadi karyawan yang berkualitas

c. Bagi Pihak Lain

Penelitian ini bisa digunakan sebagai refrensi untuk menulis penelitian lain tentang variasi tata letak dan garnish hidangan.

\section{DAFTAR PUSTAKA}

Atang Subur Safari. 2007. Manajemen Operasional Dapur. Bandung: Sekolah Tinggi Pariwisata Bandung

Bagus Putu Sudiara. 1988. Perencanaan Dapur. Bahan Penataran guru SMTK/SMK seIndonesia: Bali. BPLP

Cowie A P, 1983, Oxford Learner's Pocket Dictionary, Oxford University Press

Hernanto. 2001. Garnis Fauna Garnish Sayuran dan Buah Bentuk Binatang. Jakarta: PT. GRAMEDIA 
Marsum, W.A. 1993. Restoran dan Permasalahannya. Yogyakarta: Andi Offset

Moh. Nazir. Ph. D. 2003. Metode Penelitian. Jakarta: PT. Ghalia Indonesia

Tim Penyusun, Kamus Pusat Pembinaan dan Pengembangan Bahasa. 1993. Kamus Besar Bahasa Indonesia. Jakarta 
